\title{
ARTICLE
}

https://doi.org/10.1057/s41599-019-0215-z

\section{Evidence-based dialogue: the relationship between religion and poverty through the lens of randomized controlled trials}

\author{
Clemens Sedmak ${ }^{1}$
}

\begin{abstract}
Rather than speculating about the relationship between poverty and religion or making use of anecdotal knowledge, it seems to be a more transparent way to make use of empirical evidence and the empirically obtained insights into the relationship between religion and poverty. Of particular interest is the role of religious institutions and religious beliefs in poverty reduction efforts. One systematic way to explore empirical findings is the use of a specific database, namely the database of the Abdul Jameel Poverty Action Lab-this is the premier institution for empirical and policy-oriented poverty research, committed to the "gold standard" of recent poverty research, Randomized Controlled Trials (RCTs). The database of the Jameel PAL rendered 14 studies (with a total of 18 research papers). Some of them were not sufficiently relevant for the topic; as such, in this study 11 of these studies are considered and the key findings of them are reconstructed insofar as they relate to the link between religion and poverty. This will be my first step. In a second step this paper offers some comments based on these studies and look at the relationship between religion and poverty more broadly; finally, some conclusions for poverty alleviation are presented.
\end{abstract}

\footnotetext{
${ }^{1}$ University of Salzburg, Salzburg, Austria. Correspondence and requests for materials should be addressed to C.S. (email: clemens.sedmak@sbg.ac.at)
} 


\section{Introduction}

ather than speculating about the relationship between poverty and religion or making use of anecdotal knowledge, there seems to be a more transparent way to make use of empirical evidence and the empirically obtained insights into the relationship between religion and poverty. I am particularly interested in the role of religious institutions and religious beliefs in poverty reduction efforts.

One systematic way to explore empirical findings is the use of a specific database, namely the database of the Abdul Jameel Poverty Action $\mathrm{Lab}^{1}$; this is the premier institution for empirical and policy-oriented poverty research, committed to the "gold standard" of recent poverty research, Randomized Controlled Trials (RCTs). RCTs emerged from the medical field, with the evaluation of streptomycin for the treatment of tuberculosis by the British Medical Research Council in 1948 (Bothwall and Podolsky, 2016). Important questions to be asked when working with RCTs refer to the validity of the chosen methodology, the magnitude and precision of the treatment effect, and the applicability of research results (Akobeng, 2005). There are a number of valuable critical meta-discussions on the limits of RCTs, especially when applied to poverty research (Tollefson, 2015). However, there are good grounds to take systematically generated data seriously, especially if patterns emerge on a comparative metastudy level that discusses a variety of studies.

For this study the database of the Jameel PAL was searched using the keywords "religion" and "religious", which rendered 14 studies (with a total of 18 research papers). Some of them were not sufficiently relevant for the topic and I will consider 11 of these studies, which I will reconstruct in their key findings insofar as they relate to the link between religion and poverty. These studies examine different aspects related to poverty: lack of resources and money, education, health or political participation. In a second step I will offer some comments based on these studies and look at the relationship between religion and poverty more broadly. Finally, I will offer some conclusions for poverty alleviation.

There are obviously limitations to this kind of study presented here. The first limitation is that no coherent concepts of religion and poverty are applied. The studies examined all use their own definitions of these concepts and although there is some significant overlap in this respect, Most studies refer to an institutionalized religion such as the Islam or Hinduism. They also do not utilize the same concept of poverty. As research has impressively shown poverty is an umbrella term, which is not limited to a lack of money but also includes other personal, social and cultural dimensions. The Jameel PAL itself does not follow a single definition of poverty and Abhijit Banerjee and Esther Duflo, its directors, have emphasized the multidimensionality of poverty and its close relation to nutrition, health or education (Banerjee and Duflo, 2012). The second limitation is the concentration of studies included in the database of the Jameel PAL. There are many more studies on the relation of religion and poverty available from different disciplines, utilizing different methodologies and researching different contexts (Tomalin, 2013). The focus on studies included in the database of the Jameel PAL is motivated by the goal to specifically look into RTCs. The third limitation is that only eleven studies are examined here. This is a rather small sample size, especially if compared to the dozens of studies on religion and poverty outside of RTCs. Thus the conclusions drawn from this small sample cannot be generalized.

Despite these limitations it seems plausible and valuable to examine the studies included in the Jameel PAL, which include a reference to religion. They provide one particular important source to examine the relation of religion and poverty, which should be complemented in further research with other sources outside of RCTs to get a more nuanced picture.

\section{Key findings in empirical poverty research}

I will provide an overview of eleven RCT-based poverty studies categorized as relevant for "religion" or "religious:"

(1) A field experiment on Business Training for women in Ahmedabad, India, conducted by Erica Field, Seema Jayachandran and Rohini Pande, produced two research papers (Field et al., (2010), Field et al., (2016). These papers discuss the religious restrictions imposed on women's business activities. Traditional religious and caste institutions, especially for women from higher casts, put constraints on their entrepreneurial agency since they are not permitted more than limited contact with men and are denied significant mobility outside of the home. Muslim women face restrictions, not so much within the sphere of kinship, but with people outside. The experiment evaluated religious restrictions according to five norms, including the abilities to socialize alone, to leave the house alone, or to speak directly to elders. The field experiment consisted in a business training intervention (a two days training module about good financial practices); the members of both the treatment group and the control group were divided into three categories: Muslims, Hindu Upper Castes, Hindu Lower Castes. Results reveal "that training led to a significant increase (13 percentage points) in the likelihood of taking out a loan within four months of training" among Upper Caste Hindu women (Field et al., 2010, p. 3). There was no effect on borrowing on the other two groups. Given the homogeneous nature of the three groups of women (homogeneous with respect to education, household wealth and types of businesses), the religious difference becomes significant. There are a number of open questions, but it can be shown that Muslim women, even though they are faced with a high number of restrictions, are less restricted in the activities that are most relevant for business in comparison to Upper Caste Hindu women. "The training helped women whose business had been held down by social restrictions, but women subject to extreme restrictions had too little agency to easily change their aspirations or activities" (Field et al., 2010, p. 5). A random subsample of this field experiment was invited to attend the training session with a friend. The "friendship at work"-intervention significantly increased participants' business activity; those trained with a friend were more likely to take out a business loan and to increase business activity. The effect was most significant among women who were subject to social and religious norms that restrict female mobility (Field et al., 2016).

(2) Leonardo Bursztyn et al. (2015) conducted a field experiment with a large Islamic bank in Indonesia, researching the role of moral appeals in credit card repayments. Clients in a treatment group whose credit card repayments were overdue received a text message two days before the end of a ten-day-grace period. "The text uses a quote from the Shahih al-Bukhari, one of the most widely used sources of Islamic law, which is well known and widely recognized among Indonesian Muslims: The Prophet (Peace and blessings be upon Him) says: /non-repayment of debts by someone who is able to repay is an injustice." (Imam alBukhari) Please repay your credit card balance at your earliest convenience. Call [customer service number]" (Bursztyn et al., 2015 , p. 2). The result was an increase by $20 \%$ of customers meeting their minimum payments. This moral appeal proved to have a stronger effect than even financial incentives; however, interestingly enough, the removal of the religious referents from the quote in the text message did not change the effectiveness of the moral appeal: "a non-religious moral statement was just as 
powerful was the same moral statement identified as a quote from the Prophet, attributed to a well-known religious text" (ibd., 4).

(3) Abhijit Banerjee et al. (2009) investigated the malleability of voting behavior given the strong tendency of ethnic voting according to caste-affiliations in rural India. In the 1980s and 1990s caste parties have been formed to encourage "caste voting;" many voters tend to support the party "that is thought to represent their caste" (ibd., 5). This is not only an issue of consolidated segregation, but also of political integrity: "Accompanying the realignment of the party system has been a striking increase in [the] prominence of criminals among the ranks of elected officials" (ibd., 7). The researchers conducted a randomized evaluation of two voter mobilization campaigns implemented by an NGO. They had planned these campaign interventions in cooperation with his local NGO partner. "One campaign primed voters to not vote on ethnic lines and the other primed voters to not vote for corrupt candidates" (ibd., 2-3). They used meetings, posters and a puppet show as the main elements of the campaign intervention. Whereas the corruption campaigning had no significant impact on electoral outcomes, the caste campaigning was effective: "The data show that while $57.6 \%$ of voters voted for their caste preferred party in control villages, this figure drops approximately by $10 \%$ in the treatment villages" (ibd., 3). The evaluation found strong evidence that ethnic preferences are malleable; the experiment also showed that reductions in ethnic voting reduce the vote share of politicians with a criminal record.

(4) Hanna and Linden (2012) investigated the pygmalion effect (the correlation between teachers' expectations and students' performances) in India. They designed an experiment: they recruited children to compete for a significant prize (worth more than half of the parents' monthly income). Families were invited by a project team that went from door to door to allow their children to enter a testing session whereby the prize money would go to the highest scoring child in each of two age groups; they recruited teachers and equipped them with a set of exams; they randomly assigned a candidate's characteristics (age, gender, caste) to the cover sheets of the exams that would be graded by the teachers. Over a 2-week-period 69 children attended 4 testing sessions. Each participating teacher was asked to grade a packet of exams (packets of 25 exams were randomly put together in different configurations); each exam was graded by an average of 43 teachers. The research, in the whole, found "evidence of discrimination against lower caste children," even though the difference is small, a difference of about 1.5 exam percentage points (Hanna/Linden, 2012, p. 148). These discriminatory patterns, so the authors of the study, seem small, but they are indicative of practices of discrimination in other areas as an expression of systemic and structural discrimination.

(5) Yusuf Neggers (Neggers, 2015; Neggers, 2016) has carried out a study involving more than 4000 voters and more than 900 polling station officers to estimate the effects of ethnic diversity among polling station officials during the 2014 parliamentary elections in India, specifically in two districts in Bihar; these officials have been randomly assigned by the government to their team. The study was particularly interested in the situation of Muslims and Yadavs, a lower-caste Hindu group. The presence of officers of a minority religious or caste identity within teams influenced the voting behavior, leading to an average shift in vote share margin of 2.3 percentage points toward the political parties traditionally associated with these groups. Neggers showed ingroup favoritism; "election officers exhibit religious/caste bias on election day and attempt to influence the behavior of potential voters" (Neggers, 2015, p. 4). Neggers, as a result of his study, encourages caste diversity within polling station teams as well as a reduction of the scope for officers' discretion. The latter point is important since he could show that polling station officers "are 10 percentage points ... more likely to assess individuals favorably in terms of qualification to vote when they are of the same religious/ caste-group type" (ibid., 5). Officers have behavioral options and can make access to voting more or less difficult, i.e. they have significant scope for discretion (ibd., 13). As a general conclusion, the findings of the study "demonstrate that institutions which require greater discretionary decision making by bureaucrats or other government employees may be more susceptible to adverse impacts of these individuals' underlying preferences and biases on the quality of public services" (ibid., 35).

(6) Duflo et al. (2017) looked into the consequences of (4 years) secondary school scholarships (that would cover tuition and fees) awarded to 682 students by lottery among 2064 Ghanaian students (aged 17 in average) from 177 schools across 5 regions of rural southern Ghana, who were admitted to a specific school but could not enroll owing to a lack of funds. The baseline study was carried out in 2008, an in-person-follow up survey was carried out in spring 2013, two follow up surveys by phone in spring 2015 and spring 2016 respectively. The average age in spring 2016 was 25 . For the whole sample, scholarship winners were 26 percentage points (55\%) more likely to complete secondary school, obtained 1,26 more years of secondary education, scored better on a reading and a math test, and adopted more preventative health behavior. The scholarship increased tertiary enrollment by 3.0 percentage points. Scholarships did not have significant effects on men in term of relational behavior, but in the case of women, scholars delayed marriage and reduced unwanted pregnancies. The number of children of women with scholarships went down significantly. It can be assumed that the changed status of women would also have an effect on religious practices.

(7) Barnhardt (2009) provides experimental evidence about the impact of neighbor diversity on inter-religious attitudes. In a large Indian city Hindus and Muslims were randomly assigned units in a public housing complex which created a natural experiment that the study could exploit. The relocated persons were fire victims whose shelters burned down in a severe fire in a slam on the south side of the city of Hyderabad in the state of Andhra Pradesh. 1363 households were surveyed in terms of their attitudes about members of other religions. The study shows that increased proximity and interaction affects attitude: a higher level of interaction with Muslims improves Hindus' explicit attitudes about Muslims. There is also a significant reduction in implicit bias among Hindu children (making use of an implicit association test); no significant effects could be observed for Muslims (the minority), but it has to be said, that in this setting, "Hindus have lower opinions of Muslims than Muslims have about Hindus. The change in Hindus' attitude that comes from contact brings their attitudes up closer to Muslims"' (Barnhardt, 2009, p. 5). This may also be a result of the majority status of Hindus: "My results suggest Hindus learn about Muslims by living together, but Muslims do not acquire new information about Hindus this way and their attitudes remain largely unaffected. It would not be surprising to find Muslims are better informed about Hindus through general activities and the media, since Hindus are the overwhelming majority population in India" (ibid., 30). Barnhardt's study also draws on Ashutosh Varshney's study on Hindu-Muslim conflicts which offered similar conclusions (Varshney, 2002).

(8) Gharad Bryan, James Choi and Dean Karlan measure the impact of faith-based livelihoods and health programs in an ongoing project in 320 communities in the Philippines (with a total of 8000 participants from Mindanao and Negros Islands); by doing this they explore the question whether religious practice and belief can improve the lives of poor people looking at character traits, social capital, economic self-sufficiency, health, 
personal happiness, social attitudes, and religious belief and engagement. The researchers want to provide the first rigorous evaluation to investigate whether teaching religious values to the ultra-poor impacts their lives. The study evaluates a 16 week Transformation Program by a faith-based organization, International Care Ministry. There are no results as yet. This is obviously not yet a robust study, but I put it in because of the relevance of the topic.

(9) Karlan et al. (2017) explore the religious norms in the demand for credit. They operate with the assumption that social norm and religion is a relevant variable in researching credit markets. Religion can influence indirect costs of borrowing, but can also generate indirect benefits. The discourse on financial inclusion has to consider religious aspects: "in Muslim-majority countries, which constitute over 1.4 billion people, we observe financial inclusion rates, such as the proportion of the population having borrowed from a bank, 24 percent below that of nonMuslim countries after controlling for GDP per capita" (ibd., 2). The study conducted a randomized experiment in Jordan, in collaboration with a microfinance institution that introduced a new loan product (that adheres to the Islamic prohibition on the use of interest costs in lending through the use of a bank fee structure). The study showed "that $18.4 \%$ of individuals offered a conventional loan apply, whereas $22.0 \%$ of individuals offered an Islamically permissible ("sharia-compliant") product apply" (ibd., 3). Hence, consumers offered a sharia-compliant loan (i.e. a loan with a different contractual structure that avoids interest) increase their application rate from $18 \%$ to $22 \%$. There was no evidence that the entity certifying the religious acceptability counted as an important factor (in fact, details about the authorizing religious authority would lead to a lower application rate, even though statistically not significant). An interesting result of the study was price-sensitivity among religious people: "We find that as the price of the sharia-compliant loan increases the demand for that product decreases, in line with basic economic theory. On the other hand, we find that religious individuals are half as price sensitive: their demand for the sharia-compliant product goes down more slowly as the price increases" (ibd., 4). There is a small increase in requested loan seize for those clients who are informed of the religious authorization.

(10) Cole et al. (2013) explore barriers to household risk management, i.e. rainfall insurance in India. Rainfall is the primary determinant of income variability in the areas studied; even though there was no explicit link to religion the findings are relevant for a study of the relationship between religion and poverty since the major factor that emerged in assessing the limited adoption of financial products to protect a household from risks was: trust. "Households do not fully trust or understand the insurance product" (Cole et al., 2013, p. 105). Trust is a major factor in contexts of limited literacy and numeracy. The researchers conducted field experiments in 50 villages with 50 villages as the control group in Andhra Pradesh and Gujarat. Low prices of rainfall insurance alone "are unlikely to be sufficient to trigger widespread index insurance adoption" (ibd., 106); next to trust, issues like liquidity constraints and financial literary pose major obstacles to obtaining insurance coverage. The project experimented with 660 home visits through insurance educators, some of which were endorsed by a local financial institute. In another experiment they used portable video players to play a message to households. They also distributed flyers and in this case religion was considered explicitly as an element of group identity: "A photograph on the flyer depicted a farmer in front of a Hindu temple ... a Mosque ... or a neutral building" (ibd., 117). "We find that, among households receiving a group emphasis flyer, households identified as Muslim have a large and statistically significantly lower insurance take-up rate when the flyer includes Hindu symbols (by 32.8 or 34.2 percentage points compared to the neutral flyer). Symmetrically, for Hindu households, take-up is statistically significantly lower when the flyer includes Muslim symbols (by 10.1 or 9.6 percentage points)" (ibd., 122). By way of conclusion, "these results provide some evidence that emphasizing the communal nature of insurance stimulates demand for insurance products, but not if those cues emphasize group members different from the household" (ibd., 122f; cf. ibd., 125). In self-reported explanations for non-purchase of insurance lack of funds but also lack of trust in the product (and the real commitment to payouts) were mentioned (ibd., 130). Price reductions are clearly not enough; there has to be an appropriate level of trust in the product and its administrators. The product needs to develop a track record and it is helpful to have local authorities endorse it.

(11) Chinhumba et al. (2014) conducted research in the demand for medical male circumcision in Malawi. Medical male circumcision is desirable since it reduces the likelihood of contracting HIV/Aids by up to $60 \%$. The design of the study was straight forward: "A baseline survey was conducted among a representative sample of approximately 1600 uncircumcised adult men in the catchment area of the clinic. At the end of the baseline survey, each respondent received a voucher for a subsidized male circumcision at the local partner clinic with the amount of the vouchers randomly assigned. In addition, approximately half of the men were told detailed information about male circumcision and HIV transmission. Data from the clinic were collected and follow-up interviews conducted one year later, indicating whether men had been circumcised" (Chinhumba et al., 2014, p. 153). The researchers experimented with a subsidy and with providing additional information-which both had an impact on the circumcision rate. The interventions had no impact on religious and cultural norms around circumcision; in other words: free services are not enough. Religions play a major role, "the rate of male circumcision is...highly correlated with religion" (ibd., 155). Culture and religion were named as the most important causes of unwillingness to be circumcised (ibd., 161, 170) next to "fear of pain." These "most common barriers to male circumcision-fear of pain and cultural or religious norms-are not affected by price or information" (ibd., 172). This points to what the researchers have called "costs," psychological costs or costs related to strong cultural or religious norms (ibd., 173).

\section{Religion and poverty: politics and culture}

After having reconstructed eleven empirical studies I would like to make a few more general observations in the light of these studies:

Religion and other elements of human existence such as politics, culture and ethics cannot always be separated. In fact, it may be part of a lived religion to become an indispensable element of ethics, culture, and politics. This could be called "the blurred boundaries effect." The boundaries between religious and other aspects of public life can get blurred as the studies referring to the caste system demonstrate (studies $1,3,4,5$ ). Due to this effect, the answer to the question of where ethics ends and religions begins (see study 2) it not clear. Nor does it seem possible (or desirable) in certain contexts to have "religion-free politics" or "religiously neutral culture" (see study 6). Looking at the studies, the role of religion within the context of (anti-)poverty policies can be reconstructed as a source of normativity and as a source of motivation (justification).

Jaco Beyers reconstructed three main functions of religion regarding poverty: religion can redirect the poverty discourse to focus on spiritual poverty instead of material concerns; religion can influence morality, inter alia, by fostering of an attitude of 
willingness to practice generosity; religion can encourage participation in alleviating poverty (Beyers, 2014). These functions can be seen as specifications of the two main functions, providing "norms" and "incentives" with an additional "interpretative" function (referring to a religion's influence on perceptions of poverty). The interpretative function should be subsumed under the normative function, I would suggest since it tells people how poverty ought to be "read." Hence, with regard to poverty, religions provide normative guidelines as well as motivating force. By this twofold contribution religions structure human agency in its normative and motivational set up. The studies have both shown the normative relevance of religion (see studies $1,2,5,9$ ) and the motivational impact of religious factors (studies $3,8,10,11$ ). The normative dimension points both to the abstract authority of religions as systems and to the personal authority of religious leaders; the normative dimension of religions can reach a point of ultimate justification with reference to the will of God, divine commands, or a divine order. With regard to the motivational aspect of religions one could distinguish between a vertical dimension (eschatological horizons such as heaven or paradise and the avoidance of hell) and a horizontal dimension (expectations from the identity-giving religious group). Both motivational elements work together in constituting the force of religions that can move a person into particular courses of action. Religions play a role in poverty policies in terms of normativity and motivation., Or so we could infer from the studies consulted.

This twofold role of religions can be specifically situated in particular contexts-the studies have dealt with three main areas: business and finance $(1,2,9,10)$, politics and culture $(3,5,7)$, education and health $(4,6,8,11)$. This finding gives some indications about the role of religions in poverty creation, poverty stabilization and poverty alleviation. There is no doubt that religion impede certain types of behavior (see study 1) as much as it can motivate particular ways of agency. But it cannot be denied that religion is a relevant factor in poverty discourses, especially considering the fact that many people living in poverty are members of religious groups. It goes without saying that religious attitudes can (strongly) influence a person's views on poverty. A study in Italy, for example, working with a sample of 1000 persons pointed to the tendency of strong Catholic believers to adopt a rather fatalistic attitude towards poverty (Norcia and Rissotto, 2013, p. 182). Max Weber's famous thesis about the connection between wealth generation and religious affiliation can also be translated into religious roots of modern poverty policy, comparing Catholic, Lutheran and Reformed Protestant traditions (Kahl, 2005). Anthony Heath and Yaojun Li have shown in a study for the British Joseph Rowntree Foundation that the affiliation to specific religious groups correlates with the probability of poverty in the United Kingdom-least likely for people of Jewish affiliation, most likely for people from the Muslim community, Sikh community, and Hindu community (Heath and $\mathrm{Li}, 2015)$. This phenomenon can be linked not only to factors intrinsic to a particular religious tradition, but also to historically contingent factors (such as migration patterns) and discriminatory practices. Gruber (2005) suggested that active membership in a church community may be associated with positive economic outcomes because of social capital, insurance effects, emotional benefits, and general well-being effects based on religious beliefs and social experiences. There is no doubt that religions as belief-producing cultural entities influence perceptions and attitudes that in their turn influence behavior and policy. Consequently, Katherine Marshall has argued for the relevance of religions in development discourse and development practices (Marshall, 2001, Marshall, 2005). The well-known links between certain types of religiosity and violence can lead to vicious circles of poverty, underdevelopment and violence
(Casimir et al., 2014). Religion in all its ambivalence influences development, for the better or the worse, and can play a major part in development efforts (Ruben, 2011).

The studies allowed us to specify three particular areas of evidence for the impact on religion on poverty situations; we could formulate three claims against this background:

(i) Religions are relevant for poverty discourse and poverty policies because they influence business agency.

Religions have an array of traits, among them a soteriological, an ethical, an institutional and a ritual dimension; all these dimensions contribute to the normative force of religions. These norms guide not only the sphere of "the sacred," but also aspects of everyday life since religions understand themselves to be more than "an additional segment of human existence," they claim to be foundational. This is why the normative impact of religion on a person's life may express itself in restrictions on mobility and personal transaction radius (i.e., determining with whom $\times$ can have which kind of interaction when and where). Religions influence entrepreneurial activities and can work as tools for framing business activities as religious acts (Griebel et al., 2014). Religions can provide spiritual resources that serve as motivating and incentivizing factors in business life; a research study on Muslim women's entrepreneurship in Malaysia, for instance, showed the impact of spirituality on motivation, social responsibility, prioritizing the needs of family and decision-making (Grines et al., 2015). In addition, religions structure the social world of a person and influence social relations; the effect of religiously created "in group"-"out group"-effects can lead to a higher effectiveness of interventions that target social restrictions making use of in-group allies, i.e. agents belonging to the same religious group. The caste system has been recognized as a particular challenge to entrepreneurship-conducive religions, especially in that individuals belonging to a lower caste exhibit a lower propensity to becoming an entrepreneur (Audretsch et al., 2007). Religions generate beliefs about wealth and poverty and about the material world in general; these belief systems or theologies will influence aspects of entrepreneurship and financial decisionmaking. In short, religions, both in their normative and in their motivational force, shape the business life of its adherents. There is, however, a lot of research that needs to be done in the field of religiosity and spirituality on the one hand and business activities and entrepreneurship on the other (cf. Balog et al., 2013).

(ii) Religions are relevant for poverty discourse and poverty policies because they help to shape politics, especially if religions have become 'culture' which has the effect of linking religions to social life, everyday experiences and the "hidden dimensions" and "silent languages" of social interactions.

Religions provide strong identity offers, especially in contexts where religiously based social stratification has become part of the dominant culture. As we have seen from the studies, education and information may be means to challenge some of these boundaries. Religions produce persistent beliefs on the basis of a religion's influence on perception, and these beliefs, in turn, influence behavior. Religions frequently present an interpretation of the world that reconstructs the human person as a citizen of two worlds, an immanent world and a transcendent world thus offering a metaphorical reading of society and politics. John Milbank has suggested that social theories as used in politics are hidden theologies (Milbank, 1991). The normative aspect of religion will push religious people towards politically relevant positions and the motivational aspect can lead to a basis for political activism.

One important element of cultures is the negotiation of the distinction between "in-place" and "out-of-place." This distinction generates normative claims about what ought and what ought not to be the case in a particular situation. Religions shape 
the normative landscape and the boundaries between acceptable and unacceptable since religions can justify and intensify moral claims and imperatives; religions manage moral expectations and influence the perception of "decency." Studies on tax compliance, for example, have shown that a religious person tends to have a higher tax compliance performance than a non-religious person (cf. Torgler, 2003; Benk et al., 2016). The boundaries between ethics and religion, however, are sometimes blurred, either in the sense that a divine-command ethics is presented as universal ethics or in the sense that religious teachings are reduced to moral messages. Well-justified moral appeals that make reference to culturally well-placed moral systems will have an impact on human decision making and personal agency.

Religions matter culturally in the way they shape space and time; housing issues in particular matter in terms of social significance. Study 7 looked into the effects of diversity experiences in housing; deliberately mixing beneficiaries in public housing could be a way to reduce negative stereotypes about the minority" (Barnhardt, 2009, p. 31). Barnhardt et al. (2015) have explored a housing lottery in an Indian city that provided winning slum dwellers the opportunity to move into improved housing on the city's periphery. Fourteen years later, lottery winners reported improved housing, but no change in asset/income/insurance situation and even a worse social situation with the experience of increased isolation from family and caste networks and lower access to informal safety networks. The researchers showed that one third of the lottery winners never moved into the improved subsidized housing and one third eventually exited. Social networks including the social networks that are based on and sustained by religious affiliation. The strategy to reduce ethnic tensions by alternative spatial arrangements has its limits in terms of factors beyond the religious variable. This point again to the above mentioned "blurred boundaries effect" that makes it difficult, if not impossible, to isolate the religious variable.

(iii) Religions are relevant for poverty discourse and poverty policies because they influence educational ideals, educational institutions, and educational practices as well as health-related behavior, life styles, together with health-related beliefs and healthrelevant moral expectations.

The studies have shown that religions co-regulate "access" to education and health. Religions shape educational institutions and parental beliefs about education (one example, for Protestant Fundamentalism: Darnell and Sherkat, 1997); religions make statements about "dangerous knowledge," access to different types of knowledge, truth, and reason; this is to say that religions also evaluate truth claims and claims about cognitive processes which goes beyond making statements about educational institutions or curricula. Education has been recognized as the key to poverty alleviation; religions shape the education agenda also by influencing the perception of teachers; religious leaders as epistemic authorities often assume the role of teachers which, in turn, has an impact on the understanding of the teaching profession.

One discourse that cannot be separated from education is the discourse on health. Here again, we see the important role of religious leaders. They can play a major role in social change practices that are intended to reduce poverty risks. The social and structural determinants of behavior of people of a religious community can be influenced by the respective religious leader(s), for the better or the worse. But there is more to the connection between religion and health than just the person of the leader: Religions make statements about the human body, about pain and suffering, about illness and disease; these "patho-theologies" will have an impact not only on beliefs, but also on life styles. The well-known "nun study" by David Snowdon pointed to this relationship between religiously motivated life style and health (Snowdon, 2003). Religions matter for health: Gonçalves et al.
(2015) obtained 4751 papers on religious and spiritual interventions (RSI) and health and scrutinized 23 of these in depth. There is clear evidence that RSI reduce anxiety-related symptoms. The RSI focused on two areas: (i) spiritual interventions in terms of moral values, beliefs in higher powers and coping, meditation and audio-visual resources; (ii) tradition-based religious services and therapeutic models. There are issues with the quantifiability of RSIs (ibd., 2946) and the lack of standardization which calls for further studies, but there is clear evidence that religious and spiritual interventions are a relevant resource for health. Calls to strengthen the partnerships between the health care sector and faith-based groups and to utilize them to achieve global health goals are built on such evidence (Duff and Buckingham, 2015).

The three areas that can be identified as evidence-based points of contact between religion and poverty, namely business and finance, politics and culture, education and health can be seen as areas that are of high relevance for poverty alleviation; these areas could in fact be linked to the Sustainable Development Goals (business and finance: SDGs 8,12 ; politics and culture: SDGs 5,9,10,11; education and health: SDGs 3,4). Religions could be seen as important candidates for Sustainable Development Goal 17 , i.e. "partnerships for the goals." It cannot be denied that religions matter for poverty alleviation efforts (sustainable development goals 1 and 2). There is clear evidence that religions influence attitudes, practices, and institutions that make a difference for the situation and the prospects of people living in poverty. This expands claims made by previous research, which has shown the important role religions can play in sustainable development through its values, through its potential for social and ecological activism and in the realm of self-development (Narayanan, 2013).

These observations would have implications for the consideration of religious factors in designing poverty reduction policies and pro-poor development programs. Religions are not only "soft, private spiritualities," but relevant institutional stake holders that shape political conditions and cultural frameworks; religions serve as brokers of power and authority, norms and values-and these aspects are the key elements of the intangible infrastructure that influences decisions about and use of tangible infrastructures. It has also become clear that religions will not go away-in spite of the predictions of their disappearance in Enlightenment-inspired 19th century "stages theories of progress." Since religions will not go away it would be unwise to ignore them or push them into the seemingly harmless private sphere. We need a proper public discourse on religions as much as we need a proper public discourse on poverty alleviation; and it is advisable in both cases to involve the voices of those most affected and those most invested. Participatory research on religions needs then be integral part of participatory research on poverty.

\section{Conclusion: the poverty and spiritual wealth of religions}

The findings of the Randomized Controlled Trials may not seem impressive and surprising, which is part of the nature of RCTs. However, they do point to areas where there is clear evidence that religion is a relevant factor in social life and in the conditions that affect poverty. Religions provide resources and open doors, but also place hurdles in the way of poverty alleviation efforts.

From the perspective of evidence-generating research religions can be seen to be especially relevant for questions of poverty as a source of normativity and as a source of motivation. This twofold influence is particularly exercised in the three areas of business and finance, politics and culture, education and health.

The role of religions can be characterized as relevant, but ambivalent. The "ambivalence of the sacred" (Scott Appleby) does 
not go away. That is why it will not do to have a dialogue between religions and poverty studies per se; there must be a dialogue that involves the critical reflection on religions, i.e. a dialogue that engages religious studies and theology. There is much more research that needs to be done to understand the intersectionality between religion and poverty-and a lot more thinking and reflecting. To paraphrase Wittgenstein's Preface to his Tractatus: the value of Randomized Controlled Trials consists in the fact that when this evidence has been gathered and generated, it shows how little has been done.

Received: 1 November 2017 Accepted: 17 December 2018 Published online: 29 January 2019

\section{Notes}

${ }^{1}$ https://www.povertyactionlab.org

\section{References}

Akobeng AK (2005) Understanding randomized controlled trials. Arch Dis Child 90:840-844

Audretsch DB, Boente W, Tamvada JP (2007) Religion and Entrepreneurship. Jena Economic Research Papers 75. Max Planck Institute of Economics, Jena

Balog A, Baker LT, Walker AG (2013) Religiosity and spirituality in entrepreneurship: a review and research agenda. J Manage Spirituality Religion 11 (2):159-186

Banerjee A, Duflo E (2012) Poor economics: a radical rethinking of the way to fight global poverty. Public Affairs, New York

Banerjee A., Green D, Green J, Pande R (2009) Can voters be primed to choose better legislators? Experimental Evidence from Rural India. Working paper. https:/www.povertyactionlab.org/sites/default/files/publications/105_419_Can\% 20Voters\%20be\%20Primed_Abhijit_Oct2009.pdf

Barnhardt S (2009) Near and Dear? Evaluating the impact of neighbor diversity on inter-religious attitudes. http://research.economics.unsw.edu.au/ gbose/DevWorkshop/papers/Barnhardt_near_and_dear_paper.pdf

Barnhardt S, Field E, Pande R (2015) Moving to opportunity or isolation? Network effects of a randomized housing lottery in urban India. NBER Working Paper No. 21419

Benk S, Budak T, Yüzbaşı B, Mohdali R (2016) The impact of religiosity on tax compliance among Turkish self-employed taxpayers. Religions 7(4): art 37

Beyers J (2014) The effect of religion on poverty. HTS Teol Stud/Theol Stud 70:1

Bothwall L, Podolsky S (2016) The emergence of the randomized controlled trial. New Engl J Med 375(6):501-504

Bursztyn L, Fiorin S, Gottlieb D, Kanz M (2015) Moral incentives: experimental evidence from repayments of an Islamic credit card. NBER Working Paper No. 21611. Issued in October 2015

Casimir A, Nwaoga CT, Ogbozor C (2014) Religion, violence, poverty and underdevelopment in West Africa: issues and challenges of Boko Haram Phenomenon in Nigeria. Open J Philos 4(1):59-67

Chinkhumba J, Godlonton S, Thornton R (2014) The demand for medical male circumcision. Am Econ J 6(2):152-177

Cole S, Giné X, Tobacman J, Topalova P, Towsnend R/, Vickery J (2013) Barriers to household risk management: evidence from India. Am Econ Appl Econ 5 (1):104-135

Darnell A, Sherkat DE (1997) The impact of protestant fundamentalism on educational attainment. Am Sociol Rev 62:306-315

Duflo E, Dupas P, Kremer M (2017) The impact of free secondary education: experimental evidence from Ghana. https://web.stanford.edu/ pdupas/ DDK_GhanaScholarships.pdf

Duff JF, Buckingham WW (2015) Strengthening of partnerships between the public sector and faith-based groups. Lancet 386(10005):1786-1794

Field E, Jayachandran S, Pande R (2010) Do traditional institutions constrain female entrepreneurship? A Field experiment on business training in India. American Economic Review Papers and Proceedings. 100(2):125-129. May 2010

Field E, Jayachandran S, Pande R (2016) Friendship at work: can peer effects catalyze female entrepreneurship? Am Econ J 8(2):125-153
Gonçalves JPB, Lucchetti G, Menezes PR, Vallada H (2015) Religious and spiritual interventions in mental health care: a systematic review and meta-analysis of randomized controlled clinical trials. Psychol Med 45:2937-2949

Griebel JM, Park JZ, Neubert MJ (2014) Faith and work: an exploratory study of religious entrepreneurs. Religions 5:780-800

Grines F, Fares D, Meguellati A (2015) Islamic spirituality and entrepreneurship: a case study of women entrepreneurs in Malaysia. J Happiness Well-Being 3 (1):41-56

Gruber J (2005) Religious market structure, religious participation, and outomes: is religion good for you? NBER Working Paper 11377. http://www.nber.org/ papers/w11377

Hanna RN, Linden LL (2012) Discrimination in grading. Am Econ J 4(4):146-168

Heath A, Li Y (2015) Review of the relationship between religion and poverty-an analysis for the Jospeh Rowntree Foundation. Working Paper 1. Centre for Social Investigation, Nuffield College, Oxford

Kahl S (2005) The religious roots of modern poverty policy: catholic, lutheran, and reformed protestant traditions compared. Arch Eur Sociol 96(1):91-126

Karlan D, Osman A, Shammout N (2017) To borrow or not to borrow: religious norms and the elasticity of demand for credit. https:/www.povertyactionlab.org/ sites/default/files/publications/4267_To-Borrow-or-Not-to-Borrow_Osman-et. al .Feb\%202017pdf.pdf

Marshall K (2001) Development and religion: a different lens on development debates. Peabody J Educ 76(3-4):339-375

Marshall K (2005) Religious faith and development: explorations and experience. http://www.global.ucsb.edu/orfaleacenter/luce/luce08/documents/ Marshall_OsloNGObk-Junel.pdf

Milbank J (1991) Theology and social theory. Blackwell, Oxford

Narayanan Y (2013) Religion and sustainable development: analysing the connections. Sustain Dev 21(2):131-139

Neggers Y (2015) Enfranchising your own? Experimental evidence on polling officer identity and electoral outcomes in India. Working Paper. https:// scholar.harvard.edu/files/yneggers/files/enfranchising_own.pdf

Neggers Y (2016) Essays in Economic Development and Political Economy. Doctoral dissertation, Harvard University, Graduate School of Arts and Sciences

Norcia M, Rissotto A (2013) How religious faith affects beliefs on poverty: a study in Italy. Int J Social Sci Humanit 3(2):180-185

Ruben R (2011) Can religion contribute to development? The Road from "Truth" to "Trust.". Exchange 40:225-234

Snowdon D (2003) Healthy aging and dementia: findings from the Nun Study. Ann Intern Med 139(5):450-454

Tollefson J (2015) Can randomized trials eliminate global poverty? Nature 524:150-153

Tomalin E (2013) Religions and development. Routledge, London

Torgler B (2003) The importance of faith: tax morale and religiosity. Working Paper 8. Center for Research in Economics, Management and the Arts, Basel Varshney A (2002) Ethnic conflict and civic life: Hindus and Muslims in India. Yale University Press, New Haven

\section{Additional information}

Competing interests: The author declares no competing interests.

Reprints and permission information is available online at http://www.nature.com/ reprints

Publisher's note: Springer Nature remains neutral with regard to jurisdictional claims in published maps and institutional affiliations.

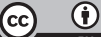

Open Access This article is licensed under a Creative Commons Attribution 4.0 International License, which permits use, sharing, adaptation, distribution and reproduction in any medium or format, as long as you give appropriate credit to the original author(s) and the source, provide a link to the Creative Commons license, and indicate if changes were made. The images or other third party material in this article are included in the article's Creative Commons license, unless indicated otherwise in a credit line to the material. If material is not included in the article's Creative Commons license and your intended use is not permitted by statutory regulation or exceeds the permitted use, you will need to obtain permission directly from the copyright holder. To view a copy of this license, visit http://creativecommons.org/ licenses/by/4.0/.

(c) The Author(s) 2019 